\title{
Niaoduqing Granules Inhibits TGF- $\beta 1$-induced Epithelial-Mesenchymal Transition in Human Renal Tubular Epithelial HK-2 Cells
}

\section{Chu-Ying Huo}

Southern Medical University

Hua-Yi Yang

Southern Medical University

Wei-Min Ning

Southern Medical University

Lin-Zhong Yu

Southern Medical University

Chun-Lin Fan

Jinan University College of Pharmacy

Jing-Yu Quan

Southern Medical University

\section{Li-Er Deng}

Dongguan Hospital of Traditional Chinese Medicine

Zhi-Ling Yu

Hong Kong Baptist University

Jun-Shan Liu

Southern Medical University

Hui-Hui Cao ( $\square$ huizizheng@hotmail.com )

Southern Medical University

\section{Research}

Keywords: chronic renal failure, Niaoduqing granules, TGF- $\beta 1$, epithelial-mesenchymal transition, TGF- $\beta$ type I receptor

Posted Date: June 12th, 2020

DOI: https://doi.org/10.21203/rs.3.rs-34640/v1

License: (c) (i) This work is licensed under a Creative Commons Attribution 4.0 International License.

Read Full License 


\section{Abstract}

Background: Chronic renal failure (CRF) is a worldwide public health burden. Niaoduqing granules (NDQ) is widely used for CRF treatment in China. However, the underlying mechanism of NDQ is not fully studied. This study is aimed to investigate whether NDQ ameliorate CRF by inhibiting TGF- $\beta 1$-induced EMT in human renal tubular epithelial HK-2 cells.

Methods: MTT assay and colony formation assay were used to investigate the cytotoxicity of NDQ in HK2 cells. Morphological changes of HK- 2 cells after TGF- $\beta 1$ or/and NDQ treatment were observed under a microscope. Wound-healing, migration and invasion assays were performed to determine the cell movement, migratory and invasive abilities, respectively. Western blot analysis was carried out to examine the protein levels of TGF- $\beta$ type I receptor (TRRI) and EMT-associated factors. Fluorescence confocal microscopy was applied to observe the organization of F-actin.

Results: NDQ suppressed T $\beta R$ I expression dose-dependently. NDQ inhibited TGF- $\beta 1$-stimulated EMT in HK-2 cells, supported by the evidences that NDQ prevented morphology change, attenuated cell migration and invasion, downregulated EMT factors and reorganized F-actin distribution in TGF- 31 -stimulated HK-2 cells.

Conclusions: NDQ attenuates chronic renal failure which may be associated with inhibition of T $\beta R I$ expression and EMT process.

\section{Background}

Chronic renal failure (CRF), a common result of chronic kidney disease (CKD), has become a health problem in the world [1]. Renal fibrosis is the main pathological feature of CRF, and inhibition of renal fibrosis is regarded as an effective therapeutic approach for CRF [2].

Emerging evidence implicates that epithelial-mesenchymal transition (EMT) of renal tubular promotes renal fibrosis. EMT is a process that epithelial cells lost their epithelial characteristics and transform into mesenchymal cells with mesenchymal characteristics. Transforming growth factor- $\beta 1$ (TGF- $\beta 1$ ) is known as a trigger of EMT and plays a pivotal role in renal fibrosis [3, 4]. Activation of TGF- $\beta 1$ mediates EMT and eventually leads to fibrosis in human renal, while inhibition of TGF- $\beta 1$ activation alters the EMT process and reduces fibrosis [5], indicating that blockade of TGF- $\beta 1$ signaling is a therapeutic strategy for CRF.

Niaoduqing granules (NDQ), a Chinese medicine preparation, which included Radix et Rhizoma Rhei, Radix Astragali, Cortex Mori, Radix Sophorae Flavescenstis, Rhizoma Atractylodies macrocephalae, Poria, Radix Paeoniae Alba, Radix Polygoni Multiflori, Radix Salviae Miltiorrhizae and Herba Plantaginis (see Additional file 1), is frequently used for CRF treatment. Clinical studies showed that NDQ reduced serum creatinine and blood urea nitrogen, improved renal function [6], and also alleviates CKD progression in patients with moderate-to-severe renal insufficiency efficiently [7]. In animal models, NDQ was found to 
reduce tubulointerstitial fibrosis and relieve CKD in rat, which were related with the modulation of TGF- $\beta$ and erythropoietin signaling pathways $[6,8,9]$. However, it's still unclear that if NDQ attenuates CRF by inhibiting TGF- $\beta 1$-induced EMT.

In this study, we first demonstrated that NDQ downregulated the expression level of TGF- $\beta$ receptor I (T $\beta R I)$ in human renal tubular epithelial HK-2 cells, inhibited TGF- $\beta 1$-induced EMT and dysregulated the distribution of filamentous actin (F-actin), which may account for the treatment of CRF by NDQ.

\section{Methods}

\section{Drug and reagents}

NDQ [National drug standard No: WS3-229(Z-033)-2000(Z)] was obtained from Guangzhou Kangchen Pharmaceutical Co., Ltd. (Guangzhou, China), and granules were dissolved in PBS at a concentration of $1.25 \mathrm{~g} / \mathrm{ml}$.

TGF- $\beta 1$ peptides was purchased from Biosynthesis biotechnology (Beijing, China). 3-(4,5-dimethylthiazol2-yl)-2,5-diphenylterazolium bromide (MTT) was obtained from Thermo Fisher Scientific (Waltham, USA). 4',6-diamidino-2-phenylindole, dihydrochloride (DAPI) was obtained from Beyotime Biotechnology (Shanghai, China). Antibodies against Vimentin, N-cadherin, snail and slug were purchased from Cell Signaling Technology (Danvers, USA). Antibodies against TGF- $\beta$ receptor I was purchased from abcam (Cambridge, UK). Rhodamine phalloidin was purchased from cytoskeleton (Denver CO, USA). Other reagents were obtained from Sigma-Aldrich (St. Louis, USA).

\section{Cell line and cell culture}

Human kidney tubular epithelial cell line HK-2 was obtained from Otwo Biotech (Shenzhen) Inc. (Shenzhen, China).

HK-2 cells were cultured in RPMI-1640 with $10 \%$ fetal bovine serum (FBS, Sijiqing, Hangzhou, China) and $1 \%$ penicillin-streptomycin (Gibco, USA) in a humidified incubator with $5 \% \mathrm{CO}_{2}$ at $37^{\circ} \mathrm{C}$.

\section{Cell viability assay}

The viability of NDQ in HK-2 cells was determined by MTT assay as previously described [10]. Cells $\left(10^{4} /\right.$ well) were seeded in 96 -well plates for $24 \mathrm{~h}$ and then exposed to different concentrations of NDQ for $24 \mathrm{~h}, 48 \mathrm{~h}$ and $72 \mathrm{~h}$, respectively. After treatment, the supernatant was discarded and $30 \mathrm{ml}$ of MTT solution $(5 \mathrm{mg} / \mathrm{ml})$ was added and incubated for another $4 \mathrm{~h}$ at $37^{\circ} \mathrm{C}$. And then, the supernatant was discarded and the purple formazan crystals were dissolved in $100 \mathrm{ml}$ of DMSO and the absorbance was measured at $570 \mathrm{~nm}$ by a microplate reader (Multiskan FC, Thermo Scientific, USA). 


\section{Colony formation assay}

HK-2 cells (300/well) were seeded in 6-well plates for $24 \mathrm{~h}$ and then treated with NDQ at different concentrations. After incubated for $24 \mathrm{~h}$, cells were washed with phosphate-buffered saline (PBS), and cultured in fresh medium for 10 days. Then, cells were fixed in $75 \%$ alcohol at $4{ }^{\circ} \mathrm{C}$ and stained with Giemsa dye [11].

\section{Cell morphological observation}

HK-2 cells $\left(10^{5} /\right.$ well) were seeded in 6-well plates and incubated for $24 \mathrm{~h}$. Cells were then serum-starved for $24 \mathrm{~h}$ followed by NDQ treatment for $24 \mathrm{~h}$ with or without TGF- 31 . After that, cells were washed with PBS and morphological changes were observed under a microscope (IX 53, Olympus, Tokyo, Japan).

\section{Cell migration and invasion experiment}

For wound healing experiment, HK-2 cells $\left(3^{\prime} 10^{5} /\right.$ well) were seeded in 6-well plates for $24 \mathrm{~h}$ and serumstarved for another $24 \mathrm{~h}$. Cells were then scratched in a straight line with 200- $\mu$ l pipette tips and treated with different concentrations of NDQ in the presence or absence of TGF- $\beta 1$. Images of HK-2 cells were acquired with a microscope (IX 53, Olympus, Tokyo, Japan) at $0 \mathrm{~h}, 12 \mathrm{~h}$ and $24 \mathrm{~h}$, respectively.

In the Transwell migration assay, HK-2 cells (105/well) were seeded in Transwell chamber with RPMI-1640 medium for $24 \mathrm{~h}$ and $400 \mu \mathrm{l}$ of RPMI-1640 medium containing 10\% FBS was added into the bottom chamber. Cells were then incubated with NDQ for $24 \mathrm{~h}$ under TGF- $\beta 1$-stimulated or unstimulated conditions, and chambers were fixed using $75 \%$ alcohol before stained with Giemsa dye. After that, cells remaining on the upper surface of the membrane were removed by wiping and the images of migrated cells were obtained under a microscope (IX 53, Olympus, Tokyo, Japan). The invasion assay shared the same method with the Transwell migration assay, the only difference was, matrigel was applied in the Transwell chamber before cells were seeded.

\section{Western blot analysis}

HK-2 cells ( $\left.3 \times 10^{5} \mathrm{dish}\right)$ were seeded in $60 \mathrm{~mm}$ dishes for $24 \mathrm{~h}$ and serum-starved for another $24 \mathrm{~h}$. After treated with different concentrations of NDQ for $48 \mathrm{~h}$ with or without TGF- $\beta 1$ stimulation, cells were harvested and washed with cold PBS, and then lysed for $15 \mathrm{~min}$ at $4{ }^{\circ} \mathrm{C}$ with RIPA buffer $(0.1 \mathrm{mM}$ phenylmethanesulfonyl foride, $0.1 \mathrm{mM}$ sodium orthvanadate, $0.1 \mathrm{mM}$ dthiothreitol and phosphatase inhibitor). After centrifugation at 13,500 rpm for $15 \mathrm{~min}$, supernatants were collected as total protein. The protein concentrations were determined by a BCA protein assay kit. The method of Western blotting was performed as previously described [12]. Protein levels were quantified by Image 1.4 .3 (National Institutes of Health, USA). 


\section{F-actin fluorescence confocal microscopy}

HK-2 cells $\left(3 \times 10^{5}\right.$ dish) were seeded in confocal dishes for $24 \mathrm{~h}$. After incubated in serum-free medium for $24 \mathrm{~h}$, cells were exposed to NDQ for another $24 \mathrm{~h}$ in the presence or absence of TGF- $\beta 1$. Cells were then fixed with $4 \%$ paraformaldehyde and permeabilized with $0.5 \%$ TritonX-100 in PBS. After blocked with 5\% bull serum albumin (BSA) for $15 \mathrm{~min}$ at room temperature (RT), cells were incubated with $100 \mu \mathrm{l}$ of rhodamine phalloidin $(70 \mathrm{nM})$ for $1 \mathrm{~h}$ at RT. Subsequently, cells were washed and counterstained with 100 $\mu \mathrm{l}$ of DAPI. The fluorescence was observed by confocal microscopy (LSM800, Carl Zeiss, Oberkochen, Germany).

\section{Statistical analysis}

All data were expressed as the means \pm SEM and analyzed by Graphpad Prism 5.0 software (Graphpad software Inc., USA). Tukey's test was used for multiple comparison. The values were considered statistically significant when $P<0.05$.

\section{Results}

\section{Cytotoxicity of NDQ in HK-2 cells}

To determine the cytotoxicity of NDQ in HK-2 cells, MTT assay and colony formation assay were used. The results showed that NDQ inhibited the proliferation of HK-2 cells in a dose- and time-dependent manner (Fig. 1A). However, NDQ exerted no significant cytotoxicity in HK-2 cells at the dosage below $5 \mathrm{mg} / \mathrm{ml}$ (Fig. 1B), and data from colony formation assay further confirmed this result (Fig. 1C). We therefore use NDQ with the dosage of $5 \mathrm{mg} / \mathrm{ml}$ for further study.

\section{NDQ downregulates the expression level of T $\beta R I$ in HK-2 cells}

TGF- $\beta 1$ signaling is considered to have a pivotal role in renal fibrosis and EMT process [5]. It is reported that the activation of TGF- $\beta 1$ signaling is initiated by the binding of TGF- $\beta 1$ ligand to T $\beta R I$ and T $\beta R I$ [13]. Therefore, we wonder whether NDQ affect the expression of T $\beta$ RI. HK-2 cells were exposed to indicated concentrations of NDQ for $48 \mathrm{~h}$, followed by Western blot analysis. As shown in Fig. 2, NDQ downregulated the expression level of T $\beta R I$ in a dose-dependent manner. Our finding suggested that NDQ may blocked TGF- $\beta 1$ signaling through repression of T $\beta$ RI.

\section{NDQ attenuates the morphological changes in TGF- $\beta 1-$ stimulated HK-2 cells}


$T \beta R I$ is critical in TGF- $\beta 1$ signaling, which mediates downstream and leads to EMT [14]. Based on the evidence that NDQ downregulated the expression level of T $\beta R I$, we suspected NDQ exerts inhibitory effects on TGF- $\beta 1$ signals and subsequently suppresses EMT in renal epithelial cells. TGF- $\beta 1$, a wellknown inducer of EMT, was added and incubated with HK-2 cells for $24 \mathrm{~h}$ after serum-starved for $24 \mathrm{~h}$ to establish a model of EMT in HK-2 cells. The morphology of HK-2 cells was changed and became slender and fibroblast-like after simulated with TGF- $\beta 1$ (Figure 3, red arrow), while NDQ prevented cells from these morphological changes.

\section{NDQ inhibits TGF- $\beta 1$-induced EMT in HK-2 cells}

To verify the effect of NDQ on TGF- $\beta 1$-induced EMT, we determined the expression levels of EMTassociated protein, including $\mathrm{N}$-cadherin, vimentin, slug and snail. Our data showed that TGF- $\beta 1$ upregulated the expression levels of N-cadherin, vimentin, slug and snail, while NDQ prevented the induction of EMT by TGF- $\beta 1$, with downregulation of the N-cadherin, vimentin, slug and snail expression levels (Figure 4).

\section{NDQ inhibits cell movement, migration and invasion in TGF- $\beta 1$-stimulated HK-2 cells}

When cells undergo EMT, cell adherence is attenuated and cell mobility is enhanced [15]. To investigate the effects of NDQ on cell movement in HK-2 cells, wound-healing assay was performed. We found that TGF- $\beta 1$ promoted cell movement, nevertheless, NDQ inhibited the TGF- $\beta 1$-induced cell movement in HK-2 cells (Figure 5A). Further evidences were provided by Transwell migration assay and invasion assay. As shown in Figure 5B, TGF- $\beta 1$ remarkably enhanced the migratory ability of HK-2 cells. However, NDQ treatment reduced cell migration. As such, the invasion assay result also demonstrated that NDQ reversed cell invasion induced by TGF- $\beta 1$ in HK-2 cells (Figure $5 C$ ).

\section{NDQ reorganized the arrangement of F-actin in TGF- $\beta 1$ - stimulated HK-2 cells}

F-actin, an important component of cytoskeleton, involves in cell migration and invasion [16]. We subsequently detected the arrangement of F-actin followed by NDQ treatment. Rhodamine phalloidin was applied to visualize the distribution of the F-actin in HK-2 cells. As shown in Figure 6, TGF- $\beta 1$ increased the expression and longitudinally distribution of F-actin. Compared to TGF- $\beta 1$-stimulated cells, NDQ treatment decreased the intensity and reorganized the distribution of F-actin in HK-2 cells. These data further validated that NDQ attenuated TGF- $\beta 1$-induced EMT in HK-2 cells.

\section{Discussion}


As a burden on global health, CRF is mainly featured by tubulo-interstitial fibrosis, regardless of the initial etiology of the renal disease. Hence, renal fibrosis is a universal feature of CRF and contributes dramatically to end-stage renal failure [17]. There are two main therapeutic strategies for CRF to improve renal function: dialysis and renal transplantation. Nevertheless, these therapies lead to the increased risk of cardiovascular problem [18]. Clinical observation showed that NDQ dramatically alleviate renal dysfunction and tubulointerstitial fibrosis for CKD patients at stage III to stage IV [19]. Previous studies about CRF treatment tended to choose NDQ as a positive medicine [20-23], indicating its certain efficacies. In this study, we demonstrate that NDQ contributes to CRF by downregulation of T $\beta R I$ expression level, inhibiting the EMT processing, and rearranging the F-actin organization.

Renal fibrosis is a characteristic by which CKD develops into CRF. Previous studies have reported that EMT is a phenotypic conversion that has emerged as a critical role in renal fibrosis and contributes to the progression of CRF [24]. TGF- $\beta 1$ has a predominant role in the progress of CRF. Accumulating evidences have pointed out that TGF- $\beta 1$ activates its downstream to contribute to EMT and renal fibrosis. TGF- $\beta$ receptors, including T $\beta R I$ and T $\beta R I I$, participates in TGF- $\beta$ signals. At the cell membrane, TGF- $\beta 1$, serving as a ligand, first binds to T $\beta R I I$, and subsequently recruits T $\beta R I$ and induces its activation. After receptor binding, TGF- $\beta 1$ exerts its cellular functions and promotes the EMT process [25]. Hence, the activation of $T \beta R I$ is pivotal in TGF- $\beta 1$ signaling. It was reported that T $\beta R I$ downregulation led to EMT suppression in TGF- $\beta$-stimulated nasal epithelial cells [14]. Previous research also suggested that suppressed TGF$\beta 1 /$ TGF- $\beta$ type I receptor/Smads signaling activation in vivo and in vitro, suppressing the EMT and collagen deposition to alleviate renal fibrosis that the inhibition of renal fibrosis was regarded as an effective therapeutic approach for CRF [26]. In this study, we first demonstrated that NDQ inhibits the expression level of T $\beta R I$ in human renal tubular epithelial HK-2 cells, while previous study revealed that NDQ downregulated the expression level of T $\beta R I$ in CRF rats [9]. We will further investigate if NDQ inhibit the membrane T $\beta R I$ levels, and the effects of NDQ on T $\beta R I$ transcription, translation, or post-translation.

The occurrence of EMT leads to the loss of epithelial markers of renal tubular cells, the development of invasive and metastatic in cells and the increased of mesenchymal features in morphology, such as spindle-cell-like morphology. Moreover, during the EMT process, the expression of the epithelial markers, including E-cadherin, is downregulated, whereas the mesenchymal markers, such as N-cadherin, Snail, Slug, and Vimentin are increased. $\mathrm{N}-\mathrm{Cadherin}$ is the main contributors to reduced cell-cell adhesion in epithelial tissues and eventually lead to cell de-differentiation, tissue disorder and increased cell invasion capacity, ultimately, to metastasis. Vimentin is an intermediate filament protein and acts as a cytoskeletal element, which is also known as a mesenchymal marker. Besides, EMT-inducing transcription factors include Snail and Slug. Especially, Snail is associated with the initial cell-migratory phenotype and is regarded as an early marker of EMT $[27,28]$. In our research, TGF- $\beta 1$ alternated the morphology of HK-2 cells, while NDQ prevented cells from these changes. It was also found that NDQ attenuated cell migratory and invasive abilities as well as inhibited TGF- $\beta 1$-induced upregulation of EMT markers including N-cadherin, Snail, Slug, and Vimentin in HK-2 cells, indicating that NDQ inhibited TGF- $\beta 1$ induced EMT in HK-2 cells. These results were in agreement with a previous study by Lu et al [29]. However, Lu et al used rat serum containing NDQ for the mechanistic study and our research is the first 
time use NDQ directly in human renal tubular epithelial cells and demonstrates its inhibitory effects on EMT.

For years, EMT is considered as a binary process with cells individually detach from tissue. However, recent studies demonstrate epithelial cells and mesenchymal cells are co-exist as a cluster in many cases, which is called hybrid E/M phenotype, and this phenotype presents more migratory and invasive properties [30]. This concept indicates an alternative EMT process in NDQ intervention. In this regard, more experiments will be needed to explore the extent of NDQ-induced EMT suppression. Recent research also suggested that transcription factors like GRHL2 or OVOL2 may be the crucial EMT drivers [31, 32], whether NDQ inhibit the expression levels of the other regulators is unknown and deserves further exploration.

F-actin is an important protein of muscle thin filaments, which constitute the eukaryotic cytoskeleton. Remodeling of F-actin facilitates cell migration and invasion [16, 33]. At the final process of EMT, the cells reorganize their cortical actin cytoskeleton to enable dynamic cell elongation and directional motility [34]. Thus, F-actin reorganization directly controls cell migration/invasion. Since EMT is characterized by increased cell migration/invasion and actin stress fiber formation, F-actin plays an important role in renal fibrosis. Our results showed that NDQ significantly reduced F-actin intensity and remodeled its organization in HK-2 cells. These evidences strongly suggest that NDQ suppresses CRF through cell migration and invasion via reorganizing the arrangement of F-actin.

It should be pointed out that once T $\beta R$ I is activated, the canonical Smad signaling and non-canonical Smad pathways are generally activated to regulate gene transcription for performing physiological functions. Although the inhibition of the protein expression of T $\beta R I$ by NDQ was demonstrated, the specific pathways that it regulates need further exploration [35-37].

\section{Conclusion}

In conclusion, we first demonstrated that the renoprotective effect of NDQ is partially attributed to the downregulation of T $\beta R I$, which account for the inhibition of TGF- $\beta 1$-induced EMT in HK-2 cells (Fig. 7). This study provides a pharmacological basis for the clinic use of NDQ in the treatment of CRF.

\section{Abbreviations}

$\mathrm{CRF}$, chronic renal failure; CKD, chronic kidney disease; EMT, epithelial-mesenchymal transition; TGF- $\beta 1$, transforming growth factor; NDQ, niaoduqing granules; T $\beta R I$, TGF- $\beta$ receptor I; MTT, 3-(4,5dimethylthiazol-2-yl)-2,5-diphenylterazolium bromide; DMSO, dimethyl sulfoxide; PBS, phosphate-buffered saline; PMSF, phenylmethanesulfonyl fluoride; ECL, enhanced chamiluminescence; RT, room temperature; F-actin; filamentous actin; DAPI, 4',6-diamidino-2-phenylindole, dihydrochloride; BSA, bull serum albumin.

\section{Declarations}




\section{Ethics approval and consent to participate}

Not applicable.

\section{Consent for publish}

Not applicable.

\section{Availability of data and materials}

The data used to support the findings of this study are available from the corresponding upon request.

\section{Competing interests}

No conflicts of interest were declared by the authors.

\section{Funding}

This work was supported by the Guangdong Province Universities and Colleges Pearl River Scholar Funded Scheme (GDHVPS2018), the National Hong Kong Scholars program (XJ2016059), the National Science Foundation of China (81602997), the China Postdoctoral Science Foundation (2016M590797), the Natural Science Foundation of Guangdong Province (2020A1515011239) and the Guangzhou Consun Pharmaceuticals Co., Ltd.. These funding bodies played no role in the design of the study; collection, analysis, and interpretation of data; and in writing the manuscript.

\section{Authors' contributions}

$\mathrm{CYH}$ and HYY carried out the experiments, data analysis and manuscript writing. WMN performed the statistical analysis and prepared figures. LZY and CLF participated in experimental work and results writing. JYQ and LED carried out the experiments and discussion writing. ZLY, JSL and HHC designed and supervised the study. All authors have read and agreed to publish this manuscript.

\section{Acknowledgements}

Not applicable.

\section{References}


1. Xiao Q, Guan Y, Li C, Liu L, Zhao D, Wang H: Decreased expression of transforming growth factor- $\beta 1$ and $\mathrm{a}$-smooth muscle actin contributes to the protection of lotensin against chronic renal failure in rats. RENAL FAILURE 2018, 40(1):583-589.

2. Sato M, Muragaki Y, Saika S, Roberts AB, Ooshima A: Targeted disruption of TGF-beta1/Smad3 signaling protects against renal tubulointerstitial fibrosis induced by unilateral ureteral obstruction. $J$ CLIN INVEST 2003, 112(10):1486-1494.

3. Kalluri R, Neilson EG: Epithelial-mesenchymal transition and its implications for fibrosis. J CLIN INVEST 2003, 112(12):1776-1784.

4. Zhao S, Jiang JT, Li D, Zhu YP, Xia SJ, Han BM: Maternal exposure to di-n-butyl phthalate promotes Snail1-mediated epithelial-mesenchymal transition of renal tubular epithelial cells via upregulation of TGF-beta1 during renal fibrosis in rat offspring. Ecotoxicol Environ Saf 2019, 169:266-272.

5. Wang W, Zhou PH, Hu W, Xu CG, Zhou XJ, Liang CZ, Zhang J: Cryptotanshinone hinders renal fibrosis and epithelial transdifferentiation in obstructive nephropathy by inhibiting TGFbeta1/Smad3/integrin beta1 signal. Oncotarget 2018, 9(42):26625-26637.

6. Wang X, Yu S, Jia Q, Chen L, Zhong J, Pan Y, Shen P, Shen Y, Wang S, Wei Z et al: NiaoDuQing granules relieve chronic kidney disease symptoms by decreasing renal fibrosis and anemia. Oncotarget 2017, 8(34):55920-55937.

7. Zheng Y, Cai GY, He LQ, Lin HL, Cheng XH, Wang NS, Jian GH, Liu XS, Liu YN, Ni ZH et al: Efficacy and Safety of Niaoduqing Particles for Delaying Moderate-to-severe Renal Dysfunction: A Randomized, Double-blind, Placebo-controlled, Multicenter Clinical Study. Chin Med J (Engl) 2017, 130(20):24022409.

8. Miao XH, Wang CG, Hu BQ, Li A, Chen CB, Song WQ: TGF-beta1 immunohistochemistry and promoter methylation in chronic renal failure rats treated with Uremic Clearance Granules. Folia Histochem Cytobiol 2010, 48(2):284-291.

9. Huang YR, Wei QX, Wan YG, Sun W, Mao ZM, Chen HL, Meng XJ, Shi XM, Tu Y, Zhu Q: Ureic clearance granule, alleviates renal dysfunction and tubulointerstitial fibrosis by promoting extracellular matrix degradation in renal failure rats, compared with enalapril. J ETHNOPHARMACOL 2014, 155(3):15411552.

10. Liu JS, Huo CY, Cao HH, Fan CL, Hu JY, Deng LJ, Lu ZB, Yang HY, Yu LZ, Mo ZX et al: Aloperine induces apoptosis and G2/M cell cycle arrest in hepatocellular carcinoma cells through the PI3K/Akt signaling pathway. PHYTOMEDICINE 2019, 61:152843.

11. Zhang D, Liu J, Deng L, Chen M, Yiu A, Cao H, Tian H, Fung K, Kurihara H, Pan J et al: Arenobufagin, a natural bufadienolide from toad venom, induces apoptosis and autophagy in human hepatocellular carcinoma cells through inhibition of PI3K/Akt/mTOR pathway. CARCINOGENESIS 2013, 34(6):13311342.

12. Lu Z, Xie P, Zhang D, Sun P, Yang H, Ye J, Cao H, Huo C, Zhou H, Chen Y et al: 3Dehydroandrographolide protects against lipopolysaccharide-induced inflammation through the cholinergic anti-inflammatory pathway. BIOCHEM PHARMACOL 2018, 158:305-317. 
13. Hwangbo C, Tae N, Lee S, Kim O, Park OK, Kim J, Kwon SH, Lee JH: Syntenin regulates TGF-beta1induced Smad activation and the epithelial-to-mesenchymal transition by inhibiting caveolinmediated TGF-beta type I receptor internalization. ONCOGENE 2016, 35(3):389-401.

14. Huang TW, Li ST, Fang KM, Young TH: Hyaluronan antagonizes the differentiation effect of TGFbeta 1 on nasal epithelial cells through down-regulation of TGF-beta type I receptor. Artif Cells Nanomed Biotechnol 2018, 46(sup3):S254-S263.

15. Li J, Zhang M, Mao Y, Li Y, Zhang X, Peng X, Yu F: The potential role of aquaporin 1 on aristolochic acid I induced epithelial mesenchymal transition on HK-2 cells. J CELL PHYSIOL 2018, 233(6):49194925.

16. Huang D, Cao L, Xiao L, Song J, Zhang Y, Zheng P, Zheng S: Hypoxia induces actin cytoskeleton remodeling by regulating the binding of CAPZA1 to F-actin via PIP2 to drive EMT in hepatocellular carcinoma. CANCER LETT 2019, 448:117-127.

17. Liu Y: Cellular and molecular mechanisms of renal fibrosis. NAT REV NEPHROL 2011, 7(12):684-696.

18. Ortiz A, Covic A, Fliser D, Fouque D, Goldsmith D, Kanbay M, Mallamaci F, Massy ZA, Rossignol P, Vanholder $\mathrm{R}$ et al: Epidemiology, contributors to, and clinical trials of mortality risk in chronic kidney failure. LANCET 2014, 383(9931):1831-1843.

19. Meng XJ, Wan YG, Wei QX, Chen HL, Shi XM, Huang YR, Yao J: [Overview research of uremic ulearance granule treating chronic renal failure]. Zhongguo Zhong Yao Za Zhi 2013, 38(21):36513655 .

20. Ma XH, He LQ: [Effect and mechanism of jianpi qinghua recipe on renal functions of adriamycininduced nephropathic rats from the angle of inhibiting renal fibrosis]. Zhongguo Zhong Xi Yi Jie He Za Zhi 2014, 34(6):733-738.

21. Wang SH, Chen BM, Liu YF, Che WP, Wu ZD, Wang GB, Xia XQ, Huang HE, Wei L, Zhu HL et al: [Effect of Paidu Baoshen Pill on renal fibrosis in 5/6 nephrectomized rats]. Zhongguo Zhong Xi Yi Jie He Za Zhi 2015, 35(1):81-87.

22. Pang LL, Hou LB, Mei QX, Kong XL, Hu Y, Gao YQ, Lin H, Liu ZH, Zeng CY, Lian YY et al: [Effects of compound Centella asiatica enema on kidneys coefficient, electrolytes and blood in chronic renal failure rats]. Zhong Yao Cai 2010, 33(5):775-778.

23. Ma Y, Hou LB, Xiao W: [Study of the Shenshuaining dispersible tablets in treating chronic renal failure rats induced by adenine]. Zhong Yao Cai 2007, 30(4):432-435.

24. Lee SI, Kim HJ, Baek MC, Park KM, Park Y, Yoon CH, Boo YC: Wen-pi-tang-Hab-Wu-ling-san, an oriental herbal prescription, attenuates epithelial-mesenchymal transdifferentiation stimulated by TGF-beta1 in kidney cells. PHYTOTHER RES 2007, 21(6):548-553.

25. Schnaper HW, Jandeska S, Runyan CE, Hubchak SC, Basu RK, Curley JF, Smith RD, Hayashida T: TGF-beta signal transduction in chronic kidney disease. Front Biosci (Landmark Ed) 2009, 14:24482465.

26. Gu TT, Chen TY, Yang YZ, Zhao XJ, Sun Y, Li TS, Zhang DM, Kong LD: Pterostilbene alleviates fructose-induced renal fibrosis by suppressing TGF-beta1/TGF-beta type I receptor/Smads signaling 
in proximal tubular epithelial cells. EUR J PHARMACOL 2019, 842:70-78.

27. Bahrami A, Majeed M, Sahebkar A: Curcumin: a potent agent to reverse epithelial-to-mesenchymal transition. CELL ONCOL 2019.

28. Lamouille S, Xu J, Derynck R: Molecular mechanisms of epithelial-mesenchymal transition. NAT REV MOL CELL BIO 2014, 15(3):178-196.

29. Lu ZY, Liu SW, Xie YS, Cui SY, Liu XS, Geng WJ, Hu X, Ji JY, Chen XM: Inhibition of the tubular epithelial-to-mesenchymal transition in vivo and in vitro by the Uremic Clearance Granule 0. CHIN J INTEGR MED 2013, 19(12):918-926.

30. Jolly MK, Somarelli JA, Sheth M, Biddle A, Tripathi SC, Armstrong AJ, Hanash SM, Bapat SA, Rangarajan A, Levine H: Hybrid epithelial/mesenchymal phenotypes promote metastasis and therapy resistance across carcinomas. Pharmacol Ther 2019, 194:161-184.

31. Roca H, Hernandez J, Weidner S, McEachin RC, Fuller D, Sud S, Schumann T, Wilkinson JE, Zaslavsky A, Li H et al: Transcription factors OVOL1 and OVOL2 induce the mesenchymal to epithelial transition in human cancer. PLOS ONE 2013, 8(10):e76773.

32. Roca H, Hernandez J, Weidner S, McEachin RC, Fuller D, Sud S, Schumann T, Wilkinson JE, Zaslavsky A, Li H et al: Transcription factors OVOL1 and OVOL2 induce the mesenchymal to epithelial transition in human cancer. PLOS ONE 2013, 8(10):e76773.

33. von der Ecken J, Muller M, Lehman W, Manstein DJ, Penczek PA, Raunser S: Structure of the F-actintropomyosin complex. NATURE 2015, 519(7541):114-117.

34. Yilmaz M, Christofori G: Mechanisms of motility in metastasizing cells. MOL CANCER RES2010, 8(5):629-642.

35. Vogelmann R, Nguyen-Tat MD, Giehl K, Adler G, Wedlich D, Menke A: TGFbeta-induced downregulation of E-cadherin-based cell-cell adhesion depends on PI3-kinase and PTEN. J CELL SCI 2005, 118(Pt 20):4901-4912.

36. Mu Y, Gudey SK, Landstrom M: Non-Smad signaling pathways. CELL TISSUE RES 2012, 347(1):1120.

37. Barrios-Rodiles M, Brown KR, Ozdamar B, Bose R, Liu Z, Donovan RS, Shinjo F, Liu Y, Dembowy J, Taylor IW et al: High-throughput mapping of a dynamic signaling network in mammalian cells. SCIENCE 2005, 307(5715):1621-1625.

\section{Figures}



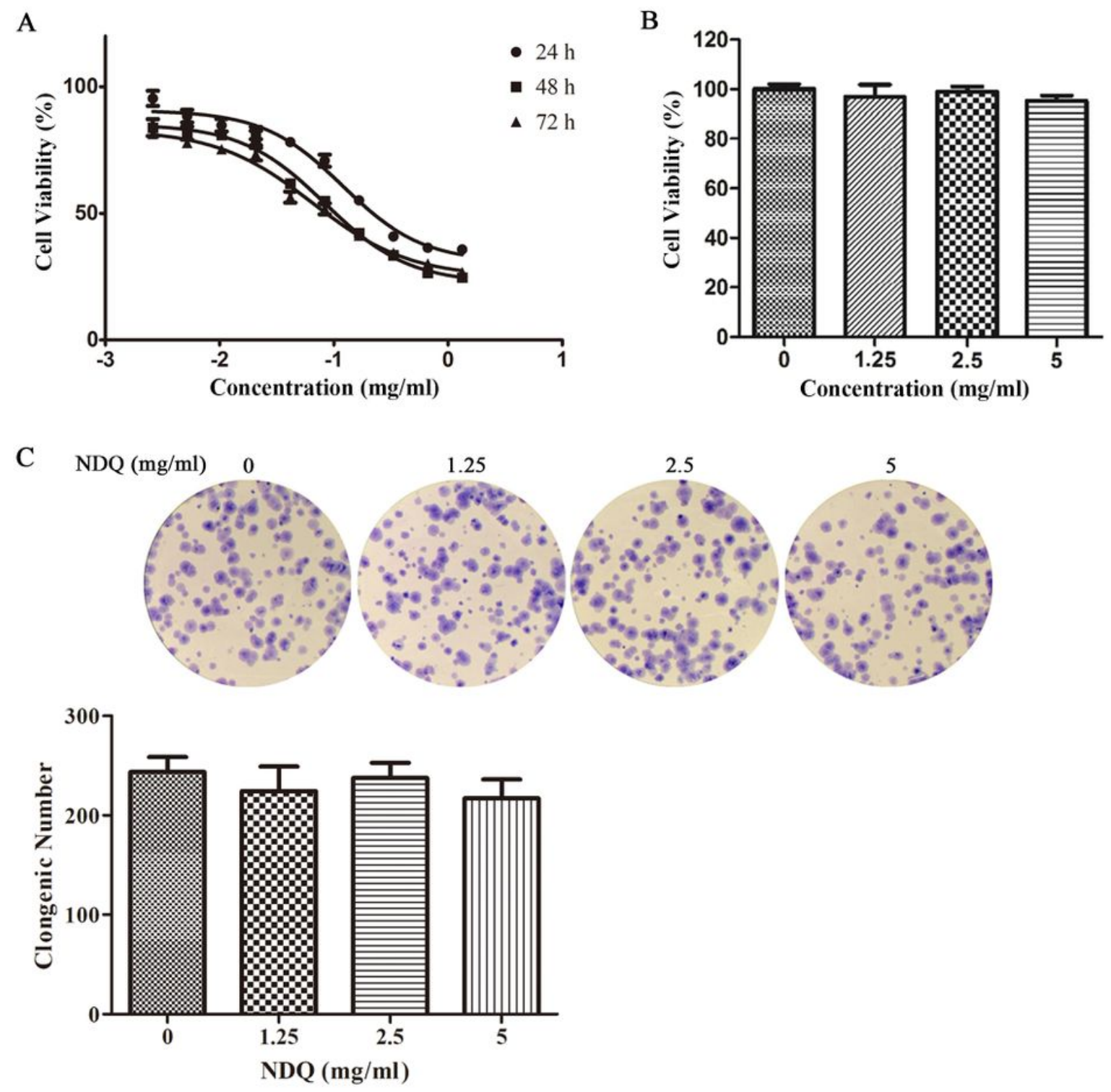

\section{Figure 1}

Cytotoxicity of NDQ on HK-2 cells. (A) NDQ inhibited the proliferation of HK-2 cells in a time- and dosedependent manner. (B) NDQ showed no significant effect on the viability of HK-2 cells at the dosage below $5 \mathrm{mg} / \mathrm{ml}$. (C) NDQ had no obvious long-term cytotoxicity on HK-2 cells at the dosage below 5 $\mathrm{mg} / \mathrm{ml}$. 

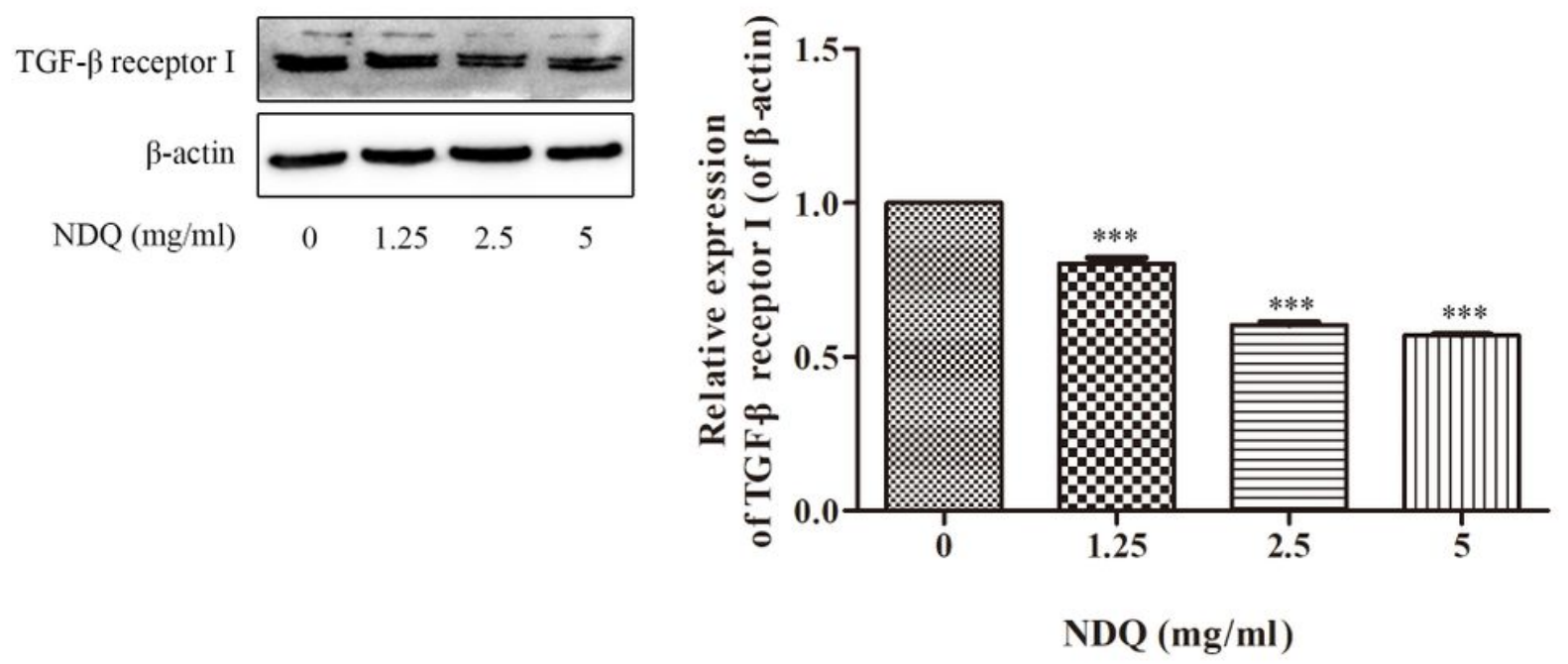

Figure 2

NDQ downregulates T $\beta R$ I expression in HK-2 cells. HK-2 cells were treated with indicated concentration of NDQ and the expression level of T $\beta R I$ was determined by Western blot analysis. The representative figures (left) and the relative expression levels analyzed by ImageJ 1.4.3 software (right) were shown. $\star \star \star P \otimes 0.001$, versus Control group. One-way ANOVA, post hoc comparisons, Turkey’s test. Columns, means; error bars, SEM. 


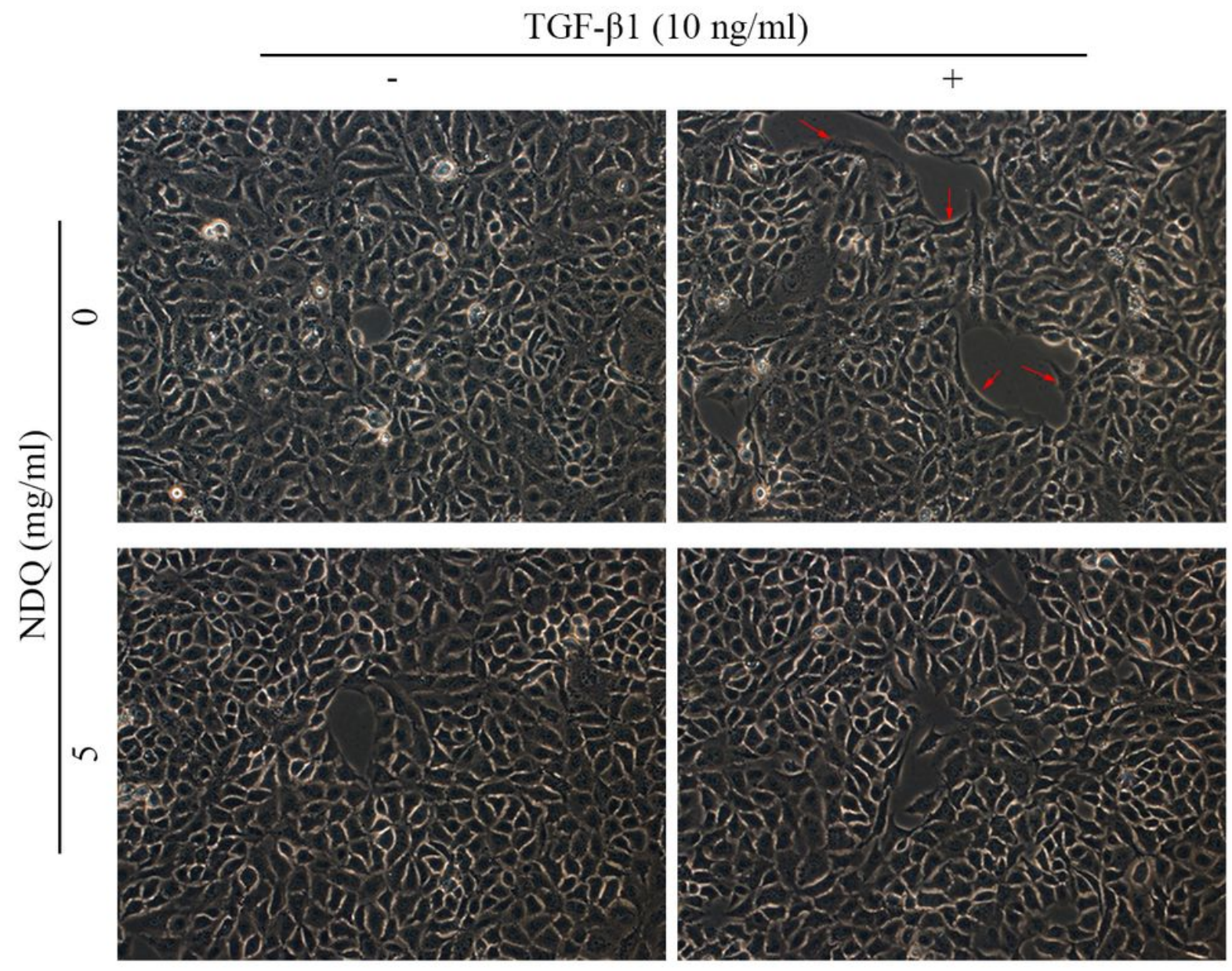

Figure 3

Morphology changes in HK-2 cells. Cells were serum-starved for $24 \mathrm{~h}$ and then exposed to vehicle or NDQ for $24 \mathrm{~h}$ with or without TGF- $\beta 1$ stimulation. Fibroblast-like morphology changes were observed in TGF$\beta 1$-stimulated HK-2 cells (red arrow), and these changes were attenuated after NDQ treatment. 


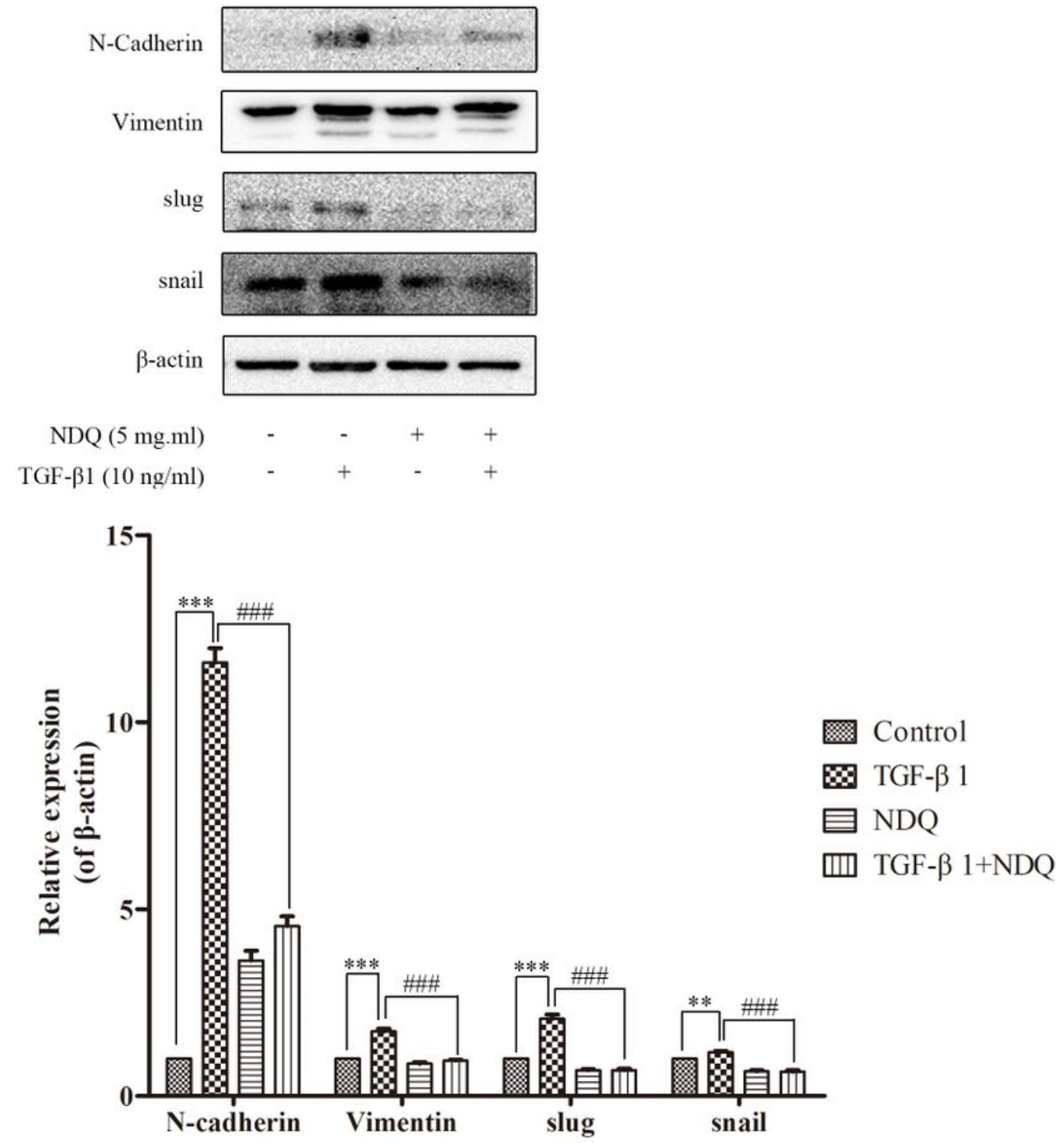

\section{Figure 4}

NDQ inhibits TGF- $\beta 1$-induced upregulation of EMT-associated factors in HK-2 cells. HK-2 cells were serum-starved for $24 \mathrm{~h}$ and then treated with indicated concentration of NDQ for $48 \mathrm{~h}$ in the presence or absence of TGF- $\beta 1$. Expression levels of N-cadherin, vimentin, snail and slug were examined by Western blotting using specific antibodies. The representative figures (upper) and the relative expression levels analyzed by ImageJ 1.4.3 software (bottom) were shown. ${ }^{*} \mathrm{P} \otimes 0.05$, ${ }^{\star \star} \mathrm{P} \otimes 0.01$ and ${ }^{\star} \star \star * P \otimes 0.001$, versus Control group. \#\#P $\triangle 0.01$ and \#\#\#P $\otimes 0.001$, versus TGF- $\beta 1$ group. One-way ANOVA, post hoc comparisons, Turkey's test. Columns, means; error bars, SEM. 

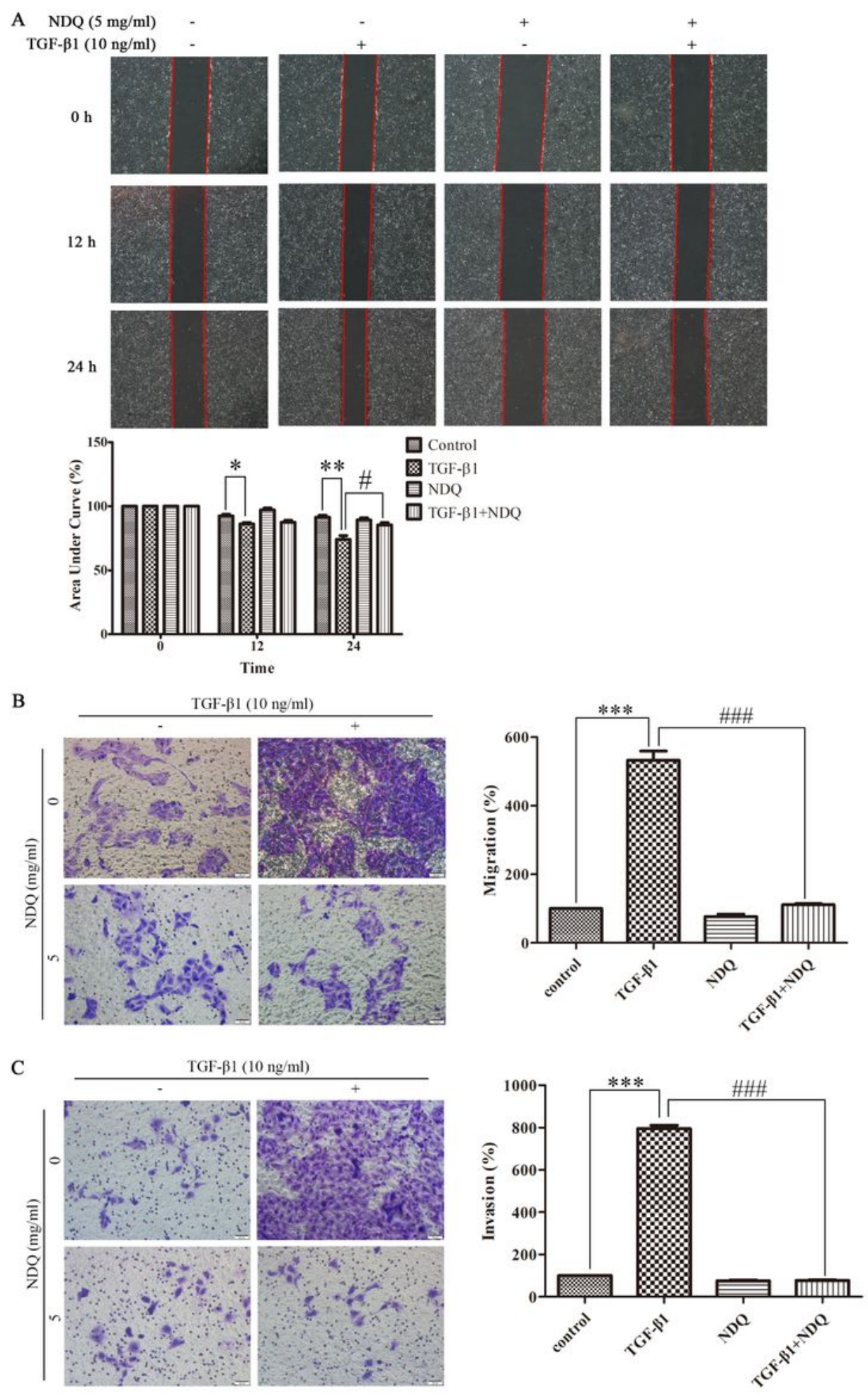

\section{Figure 5}

NDQ attenuates cell migration and invasion in TGF- $\beta 1$-stimulated HK-2 cells. Cell migration was measured by wound-healing (A) and Transwell migration assay (B), and invasive ability of HK-2 cells was measured by Transwell invasion assay (C). Relative migrated areas were quantified by ImageJ 1.4.3 software. Quantification of migrated and invasive cells were analyzed by Graphpad Prism 5.0 software. 
***P $\nabla$ 0.001, versus Control group. \#\#\#P $\nabla 0.001$, versus TGF- $\beta 1$ group. One-way ANOVA, post hoc comparisons, Turkey's test. Columns, means; error bars, SEM.

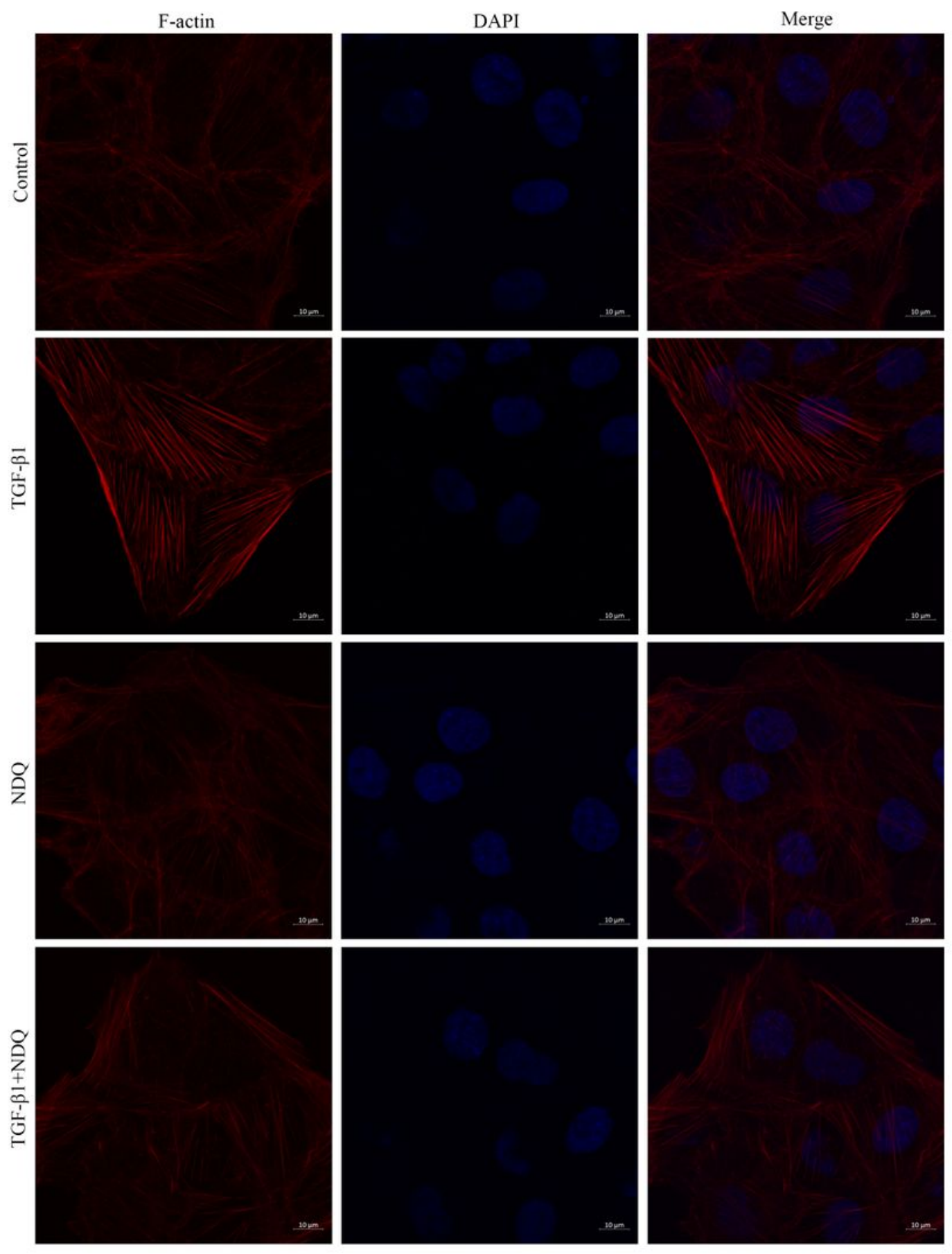

\section{Figure 6}

NDQ reorganized the distribution of F-actin. HK-2 cells were serum-starved for $24 \mathrm{~h}$ and then exposed to vehicle or NDQ $(5 \mathrm{mg} / \mathrm{ml})$ in the presence or absence of TGF- $\beta 1$ for another $24 \mathrm{~h}$, the distribution of F- 
actin was visualized by confocal after rhodamine phalloidin staining. Left: F-actin, middle: DAPI, right: merge.

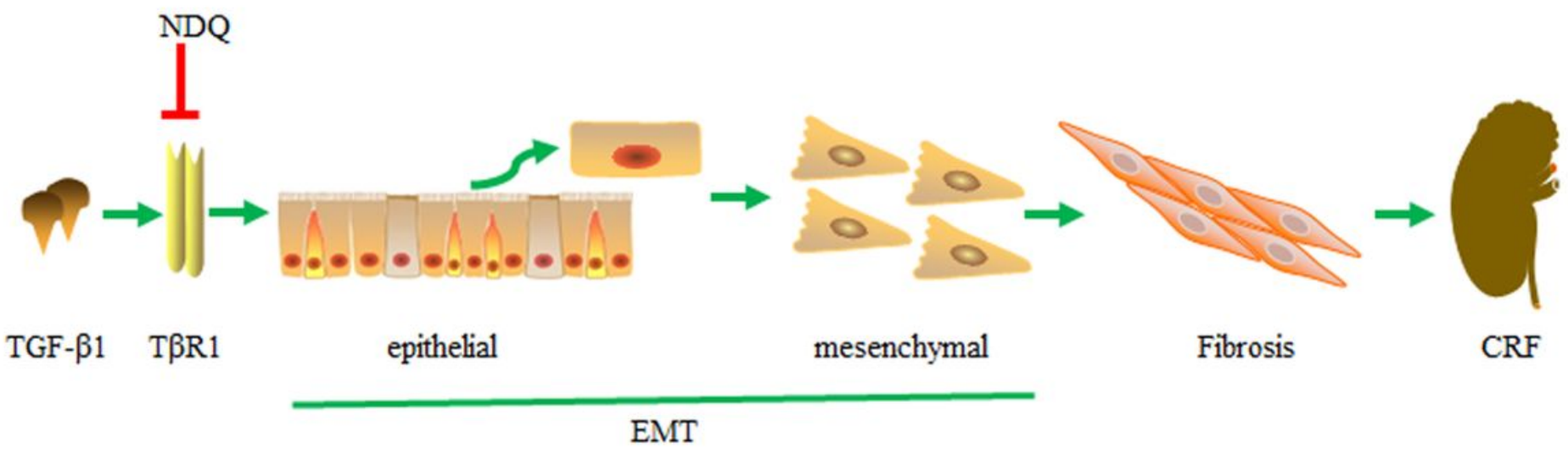

\section{Figure 7}

The underlying mechanism of NDQ on preventing epithelial cells from TGF- $\beta 1$-induced EMT. $\rightarrow$ refers to a promoting effect and $\perp$ refers to a blockage effect.

\section{Supplementary Files}

This is a list of supplementary files associated with this preprint. Click to download.

- supplement1.docx 